\title{
Classification of geothermal resources by potential
}

\author{
L. Rybach \\ Institute of Geophysics ETHZ, Zurich, Switzerland \\ Correspondence to: L. Rybach (rybach@ig.erdw.ethz.ch)
}

Received: 21 June 2014 - Revised: 13 January 2015 - Accepted: 25 February 2015 - Published: 24 March 2015

\begin{abstract}
When considering and reporting resources, the term "geothermal potential" is often used without clearly stating what kind of potential is meant. For renewable energy resources it is nowadays common to use different potentials: theoretical, technical, economic, sustainable, developable - decreasing successively in size. In such a sequence, the potentials are progressively realizable and more and more rewarding financially. The theoretical potential describes the physically present energy, the technical potential the fraction of this energy that can be used by currently available technology and the economic potential the time- and location-dependent fraction of the previous category; the sustainable potential constrains the fraction of the economic potential that can be utilized in the long term; the developable potential is the fraction of the economic resource which can be developed under realistic conditions. In converting theoretical to technical potential, the recovery factor (the ratio extractable heat/heat present at depth) is of key importance. An example (global geothermal resources) is given, with numerical values of the various potentials. The proposed classification could and should be used as a kind of general template for future geothermal energy resources reporting.
\end{abstract}

\section{Introduction}

Various possible resources reporting schemes of geothermal resources are currently under discussion, among others in UNECE (United Nations Economic Commission for Europe). Examples include

- Geothermal Reporting Code and Geothermal Lexicon for Resources and Reserves Definitions and Reporting produced by the Australian Geothermal Reporting Code Committee, 1st edition 2008, 2nd edition 2010;

- Canadian Geothermal Code for Public Reporting of Exploration Results, Geothermal Resources and Geothermal Reserves, 2010 Edition;

- "A Protocol for Estimating and Mapping Global EGS Potential" by Beardsmore et al. (2010);

- New Geothermal Terms and Definitions by the Geothermal Energy Association (GEA, 2010);

- Resource Assessment Protocol for GEOELEC (Geothermal Electricity in Europe; www.geoelec.eu) by van Wees et al. (2011).
When considering and reporting resources, the term "geothermal potential" is often used without clearly stating what kind of potential is meant. An example is presented in Table 1; here Enhanced or Engineered Geothermal System (EGS) "potentials" are listed without specifying their exact kind, for various countries. This uncertainty clearly demonstrates the need of more clarity about potentials.

For renewable energy resources it is customary to refer to different potential categories (see e.g., Voivontas et al., 1998): theoretical, technical, economic, sustainable, developable - decreasing successively in size. In this order the potentials are more and more realizable and more and more rewarding financially. The various potentials in assessing geothermal resources are described in more detail below.

\section{The various potentials}

The theoretical potential describes the physically usable energy supply (e.g., the total energy stored in biomass; for geothermal: the heat in place) over a certain time span in a given region. It is defined solely by the physical limits of use and thus marks the upper limit of the theoretically realizable energy supply contribution. Due to insurmountable technical, 
Table 1. Reported EGS potentials from various countries (from McPherson-Grant and Baria 2009).

\begin{tabular}{lcl}
\hline Location & Power (GWe) & Reference \\
\hline USA & 100 & MIT (2006) \\
Australia (part; three projects & 13 & Goldstein, personal communication \\
in south Australia) & & $(2008)$ \\
Germany & 35 & Paschen et al. (2008) \\
Switzerland (23\%) & 12 & Signorelli and Kohl (2007) \\
China (two regions) & 100 & Wan et al. (2005) \\
India (part) & 100 & Chandashekar et al. (2007) \\
Total & 360 & \\
\hline
\end{tabular}

structural and administrative limitations only small fractions of the theoretical potential can actually be used.

The technical potential describes the fraction of the theoretical potential that can be used under existing technical restrictions (currently available technology). In addition, it considers the given structural and ecologic restrictions as well as legal and regulatory boundaries, since these are similar to technical limitations - of insurmountable character. Thus it describes the time- and location-dependent possible contribution of the geothermal energy to the energy demand. Hereby the recovery factor (heat recoverable versus heat in place) becomes important. Since this potential depends mainly on technical boundary conditions it is less subject to temporal variations than the economic potential.

The economic potential describes the time- and locationdependent fraction of the technical potential that can be economically utilized within the actually considered energy system: the total costs (investment, operation/maintenance and decommissioning of a renewable energy installation) are in the same range as the total costs of competing systems. Since various approaches exist to assess the economic viability of a technology for energy supply, there are correspondingly different economic potentials. In addition several economic boundary conditions exist (e.g., oil price changes, changing levels of taxation, write-offs, feed-in tariffs).

The sustainable potential is a fraction of the economic potential; it describes the fraction that can be utilized by applying sustainable production levels. Sustainable production can be achieved with lower production rates; it secures the longevity of the resource, whereas the return of investment is slower (more details see in Rybach and Mongillo, 2006).

The developable potential describes the fraction of the economic potential that can be developed under realistic conditions (regulations, environmental and social restrictions). Therefore, it is usually smaller than the economic potential. It can be greater when administrative measures, such as promotion programs like feed-in tariffs, exist for renewable energies.

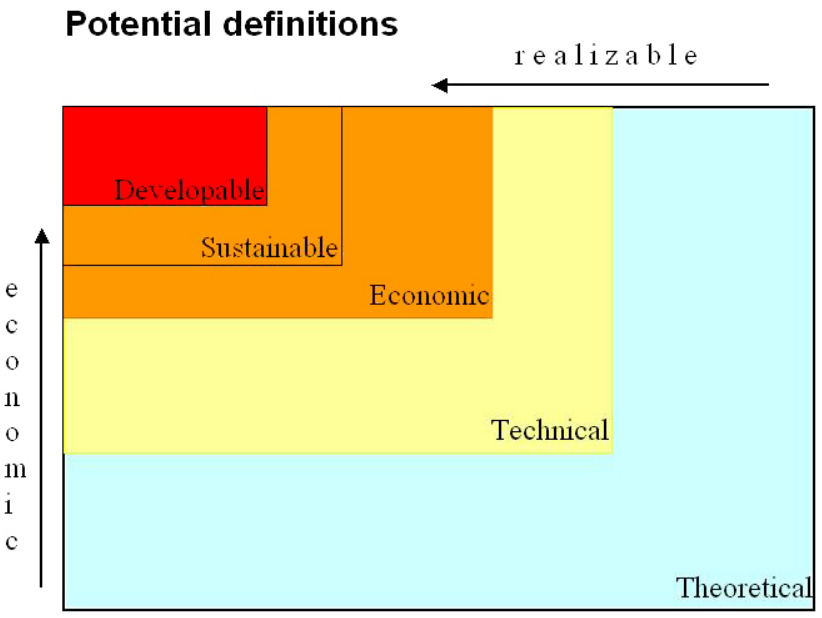

Figure 1. Potential definitions for renewable energy; they also apply to geothermal energy. From Rybach (2010).

\section{The hierarchy of potentials and interrelations}

The hierarchy and the interrelations among the various potentials are depicted in Fig. 1. The potentials are successively smaller and more economic along the above list; each potential is a fraction of the previous (except for the theoretical potential, which is the largest and least economic). In other words, the potentials form a series of nested subsets.

\section{An application example of geothermal resource classification by potential}

The above-described potential systematics is a skeleton; "tissue" (solid numbers) needs to be added to define resources and reserves. This can be done at the local, regional and global level. The following example from Goldstein et al. (2011) defines and describes global geothermal potentials, but the categorizing can also be applied to the regional or local level.

Figure 2 is from Goldstein et al. (2011), with additions (red ellipses, rectangles) to highlight definitions to be discussed. Goldstein et al. (2011) uses the potential systematics to cate- 


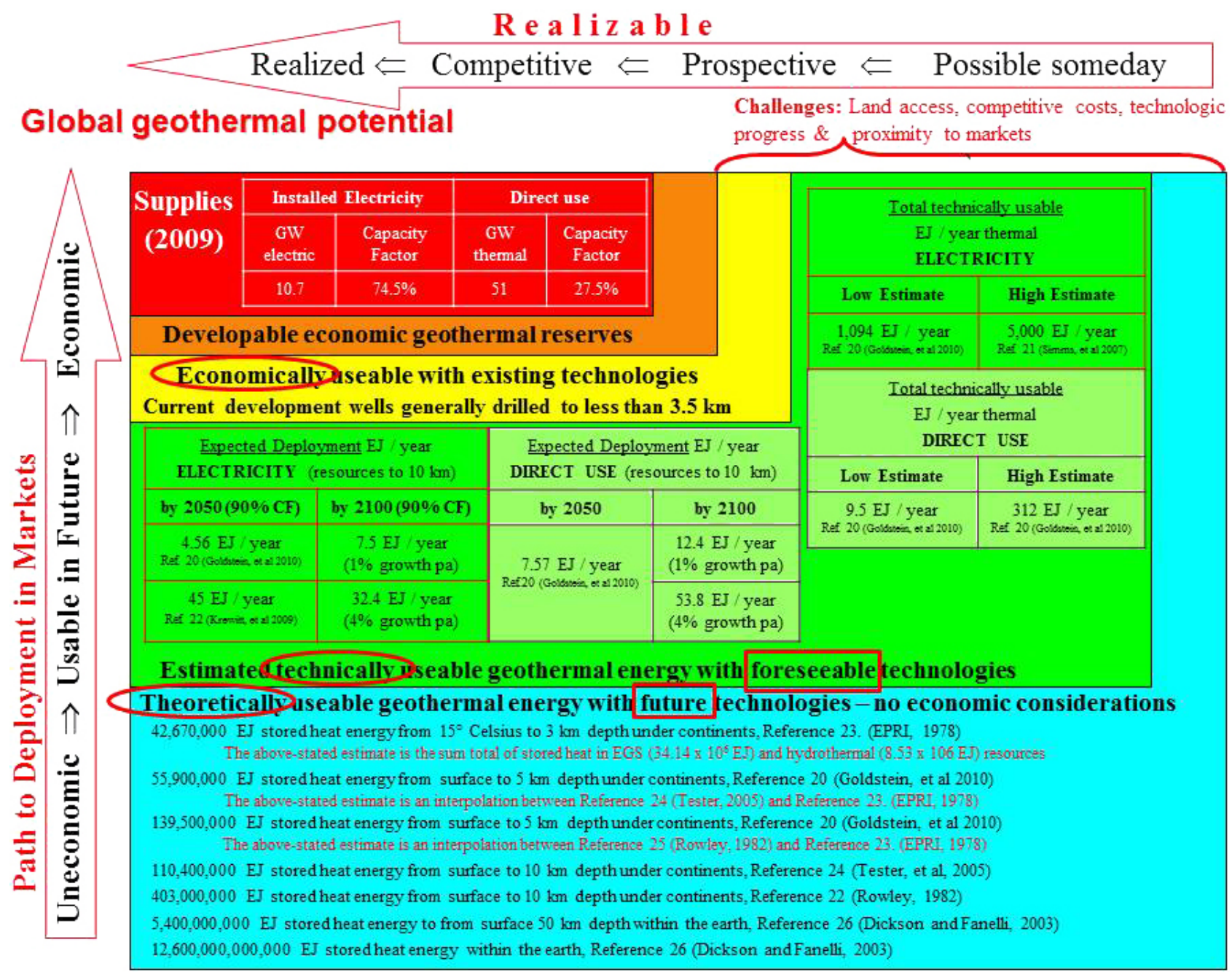

Figure 2. Potential geothermal energy resources split into categories, e.g., theoretical, technical, economic, developable and existing supplies for power generation and direct use; from Goldstein et al. (2011).

gorize geothermal resources for power generation and direct use. The figure is based on Fig. 1 of Rybach (2010).

The various subdivisions and descriptions in the figure of Goldstein et al. (2011) are discussed below, following a bottom-up approach.

\section{Discussion}

The blue box in Fig. 2 concerns the theoretical potential, i.e., the stored heat in the subsurface. It is by all means immense: most of it will remain there; even with "future" technologies it will not be usable, since complete extraction will not be possible.

The green box covers technically useable resources, applying foreseeable technology. Since it is fully uncertain what technologies might develop in the near or far future the numbers in this box are only of indicative character. The technical potential can only be realized by existing established technologies. The GEOELEC (2011) resource protocol (van Wees et al., 2011) even has a category "theoretical technical potential", which is somewhere between real, theoretical and technical potentials, i.e., not really well defined.

When it comes to converting theoretical to technical potential, the recovery factor $R$ is the key parameter: $R$ is recoverable heat (in Joules)/heat present (J) at depth. $R$ depends on the available technology of heat extraction. There is hardly any solid data for $R$, neither for hydrothermal systems nor for petrothermal/EGS. Some theoretical considerations are available (Williams, 2007). For more details see Beardsmore et al. (2010).

The next two boxes (yellow, brown) in Fig. 2 indicate the economic and developable potentials without numbers. They correspond fully to the potential classes of Rybach (2010).

Finally the topmost (red) box is assembling geothermal energy utilizations, for power generation and direct use, already 
Table 2. Evaluation of the classification by potentials in terms of the UNCF-2009 categories; from Beardsmore (2013).

\begin{tabular}{llll}
\hline Rybach (2010) classes & \multicolumn{3}{c}{ UNCF 2009 categories } \\
& $\mathrm{E}$ & $\mathrm{F}$ & $\mathrm{G}$ \\
\hline Theoretical potential & $3.2-3.3$ & $2.3-4$ & $1-4$ \\
Technical potential & $2-3.3$ & $1.3-2.2$ & $1-3$ \\
Economic potential & $1.1-2$ & $1.2-2.2$ & $1-2$ \\
Sustainable potential & $1.1-2$ & $1.2-2.2$ & $1-2$ \\
Developable potential & $1.1-1.2$ & $1.2-1.3$ & 1 \\
\hline
\end{tabular}

developed in 2011. These numbers will certainly increase in the future.

\section{Comparison with United Nations Framework Classification for Fossil Energy and Mineral Reserves and Resources 2009 (UNFC-2009) scheme}

The classification of energy and mineral resources is a generally important subject and currently on the agenda of UNECE. This body published the UNFC-2009.

The UNFC-2009 addresses mainly the classification of fossil (coal, hydrocarbon) resources; nevertheless it also provides a possible basis for a generic classification framework for geothermal energy.

Quantities in the UNFC-2009 are classified by three fundamental criteria: economic and social viability (E), field project status and feasibility (F), and geological knowledge $(G)$. Combinations of these criteria create a threedimensional framework system.

On behalf of the IEA, Geothermal Implementing Agreement (Beardsmore, 2013) undertook the task of evaluating the applicability of the UNFC-2009 scheme for geothermal energy resources. In addition, a comparison and assessment of the various geothermal reporting schemes listed in the Introduction has been attempted, with the UNFC-2009 scheme serving as the basis of comparison.

Among the other geothermal reporting schemes, the approach of classifying geothermal resources and reserves by potentials (Rybach, 2010) has also been treated in Beardsmore (2013). In particular, the following assessment is given:

The five classes of Potential proposed by Rybach (2010; Fig. 16b) define a one-dimensional scheme that covers a broad spectrum of the threedimensional UNFC-2009 classification space. The step from Theoretical Potential to Technical Potential follows the "F"-axis of the UNFC-2009 scheme, while progression from Technical Potential through Economic Potential to Developable Potential mostly tracks the "E"-axis of UNFC2009.

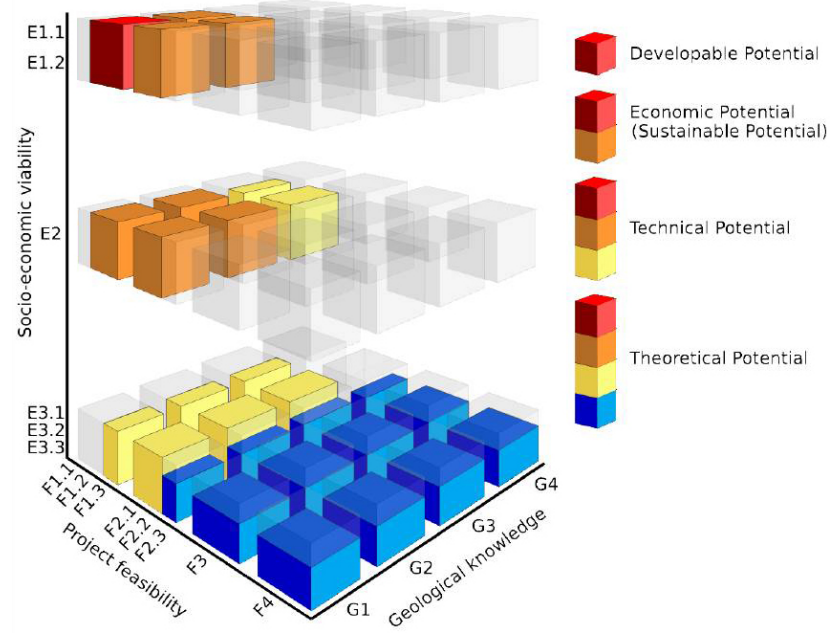

Figure 3. Mapping of Rybach (2010) classes within the UNFC2009 3-D framework; from Beardsmore (2013).

These findings are illustrated in Beardsmore (2013) by Table 2 and Fig. 3.

In addition, Beardsmore (2013) states that "Rybach's (2010) proposed classes of "potential" overlap with most categories in the other schemes. For example, technical potential in Rybach's terminology covers measured resources (Australian and Canadian reporting codes), delineated resources (GEA), and a portion of sub-marginal contingent resources (GEOELEC)". Moreover, it concludes that "Rybach's classes, therefore, provide a possible high-level tool for understanding and interpreting the inter-relationships between some of the other schemes."

\section{Conclusions}

Among the various currently discussed reporting schemes of geothermal resources, the approach by potentials is a possible, feasible option. Whenever geothermal potentials are mentioned, it should always be clearly distinguished which of the potentials is meant.

The example of Goldstein et al. (2011) demonstrates that the resources classification by various potentials is feasible and practicable. The definitions by potential of Rybach (2010) may add further value in this context.

The example mentioned above deals with global potentials; the classification by potentials can also be applied to the regional and the local level.

The proposed classification of potentials provides a useful template for standardizing the future reporting of geothermal energy resources worldwide. 
Acknowledgements. The remarks and suggestions of the two reviewers helped to improve the manuscript.

Edited by: G. Beardsmore

Reviewed by: C. Huddlestone-Holmes and C. Harvey

\section{References}

Australian Geothermal Reporting Code Committee, The Australian Code for Reporting of Exploration Results, Geothermal Resources and Geothermal Reserves, Second Edition, http://www.agea.org.au/media/docs/the_geothermal_reporting code_ed_2.pdf, last access 20 June 2014, 2010.

Australian Geothermal Reporting Code Committee, The Geothermal Lexicon for Resources and Reserves Definition and Reporting, Second Edition, http://www.agea.org.au/media/docs/ geothermal_lexicon_2010.pdf, last access 20 June 2014, 2010.

Beardsmore, G., Rybach, L., Blackwell, D., and Baron, Ch.: A Protocol for estimating and mapping the global EGS potential, Geothermal Resources Council Transactions, 34, 301-312, 2010.

Beardsmore, G.: Global Review of Geothermal Reporting Terminology - Prepared for members of the International Energy Agency - Geothermal Implementing Agreement, http://iea-gia. org/category/publications/, last access 20 June 2014, 2013.

Canadian Geothermal Energy Association. The Canadian Geothermal Code for Public Reporting, http: //www.cangea.ca/geothermal-code-for-public-reporting.html, last access 16 March 2015, 2010.

Geothermal Energy Association. New Geothermal Terms and Definitions - a Guide to Reporting Resource Development Progress and Results to the Geothermal Energy Association, 17 pp., http://geo-energy.org/pdf/ NewGeothermalTermsandDefinitions_January2011.pdf, last access 20 June 2014, 2010.
McPherson-Grant, G. and Baria, R.: Case study: The UK's First Geothermal Power Plant, GeoPower Europe Munich http://www. greenpowerconferences.com, last access 20 June 2014, 2009.

Rybach, L.: "The Future of Geothermal Energy" and Its Challenges, Proceedings of the World Geothermal Congress 2010 Bali, Indonesia, 25-29 April 2010, available at: http://www. geothermal-energy.org/pdf/IGAstandard/WGC/2010/3109.pdf, 2010,

Rybach, L. and Mongillo, M.: Geothermal Sustainability - A Review with Identified Research Needs, Geothermal Resources Council Transactions, 30, 1083-1090, 2006.

United Nations Economic Commission for Europe. United Nations Framework Classification for Fossil Energy and Mineral Reserves and Resources 2009 (UNFC-2009), ECE Energy Series No. 39. January 2010, http://www.unece.org/energy/se/reserves, last access 20 June 2014, 2010.

van Wees, J.-D., Boxem, T., Calcagno, P., Lacasse, L., and Manzella, A.: A Resource assessment protocol for GEO-ELEC. A living document produced by the GEO-ELEC Project, 23 November 2011, 18 pp., http: //www.geoelec.eu/wp-content/uploads/2012/04/GEOELEC_ RESOURCE-ASSESMENTPROTOCOL_v-16-dec-2011.pdf, last access 20 June 2014, 2011.

Voivontas, D., Assimacopoulos, D., Mourelatos, A.: Evaluation of renewable energy potential using a GIS decision support system, Renewable Energy, 13, 333-344, 1998.

Williams, C. F.: Updated methods for estimating recovery factors for geothermal resources. PROCEEDINGS, Thirty-Second Workshop on Geothermal Reservoir Engineering Stanford University, Stanford, California, January 22-24, 2007 SGP-TR-183, 2007. 